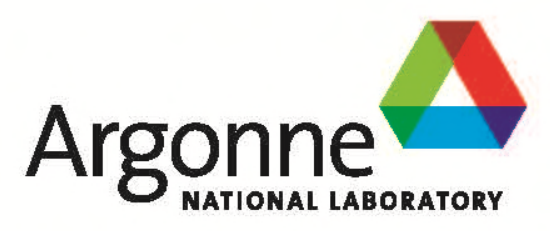

\title{
Development of ABEC Column for Separation of Tc-99 from NorthStar Dissolved Target Solution
}

Nuclear Engineering Division 


\section{About Argonne National Laboratory}

Argonne is a U.S. Department of Energy laboratory managed by UChicago Argonne, LLC

under contract DE-AC02-06 CH11357. The Laboratory's main facility is outside Chicago, at 9700 South Cass Avenue, Argonne, Illinois 60439. For information about Argonne

and its pioneering science and technology programs, see www.anl.gov.

\section{DOCUMENT AVAILABILITY}

Online Access: U.S. Department of Energy (DOE) reports produced after 1991 and a growing number of pre-1991 documents are available free via DOE's SciTech Connect (http://WwW.osti.gov/scitech/)

Reports not in digital format may be purchased by the public from the National Technical Information Service (NTS):

U.S. Department of Commerce

National Technical Information Service

5301 Shawnee Rd

Alexandria, VA 22312

unw.ntis.gov

Phone: (800) 553-NTIS (6847) or (703)

605-6000 Fax: (703) 605-6900

Email: orders@ntis.gov

Reports not in digital format are available to DOE and DOE contractors from the Office of Scientific and Technical Information (OST):

U.S. Department of Energy

Office of Scientific and Technical Information

P.O. Box 62

Oak Ridge, TN 37831-0062

unw.osti.gov

Phone: (865) 576-8401

Fax: (865) 576-5728

Email: reports@osti.gov

\section{Disclaimer}

This report was prepared as an account of work sponsored by an agency of the United States Government. Neither the United States Government nor any agency thereof, nor UChicago Argonne, LLC, nor any of their employees or officers, makes any warranty, express or implied, or assumes any legal liability or responsibility for the accuracy, completeness, or usefulness of any information, apparatus, product, or process disclosed, or represents that its use would not infringe privately owned rights. Reference herein to any specific commercial product, process, or service by trade name, trademark, manufacturer, or otherwise, does not necessarily constitute or imply its endorsement, recommendation, or favoring by the United States Government or any agency thereof. The views and opinions of document authors expressed herein do not necessarily state or reflect those of the United States Government or any agency thereof, Argonne National Laboratory, or UChicago Argonne, LLC. 


\section{Development of ABEC Column for Separation of Tc-99 from NorthStar Dissolved Target Solution}

by

Dominique Stepinski, ${ }^{1}$ Megan E. Bennett, ${ }^{1}$ Seema R. Naik, ${ }^{1}$ Lei Ling, ${ }^{2}$

$\mathrm{N}-\mathrm{H}$. Linda Wang, ${ }^{2}$ and George F. Vandegrift ${ }^{1}$

${ }^{1}$ Argonne National Laboratory, Nuclear Engineering Division, Argonne, IL

${ }^{2}$ Purdue University, West Lafayette, IN

December 2016 



\section{CONTENTS}

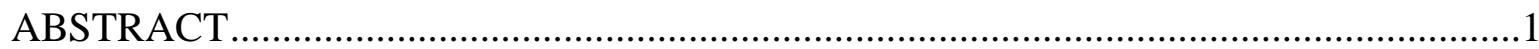

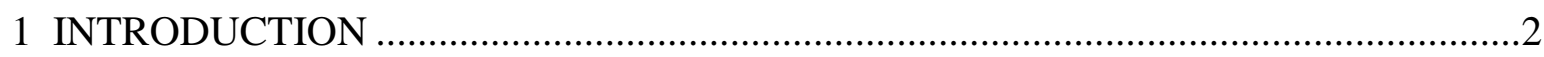

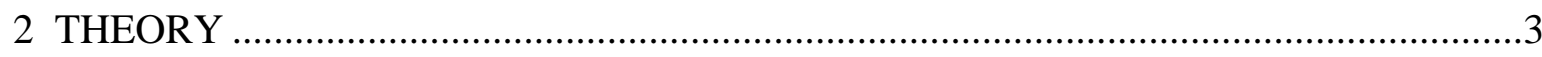

2.1 VErsatile Reaction-Separation (VERSE) Model ................................................

2.2 Langmuir Adsorption Isotherm Model .............................................................

2.3 Intra-particle Pore Diffusivity and Effective Capacity ........................................4

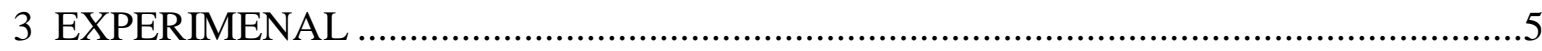

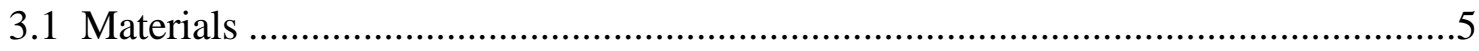

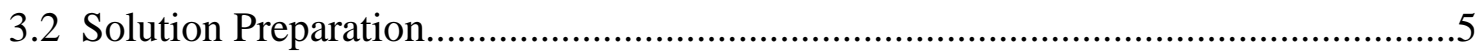

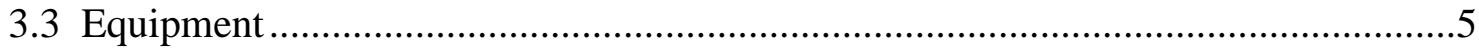

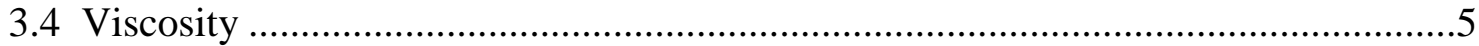

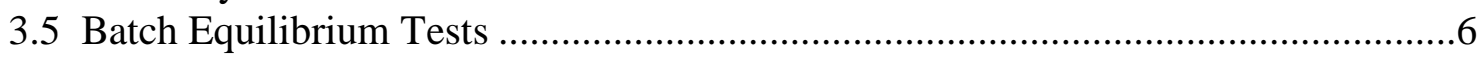

3.6 Omnifit Column Packing ..................................................................................6

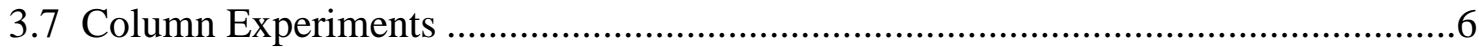

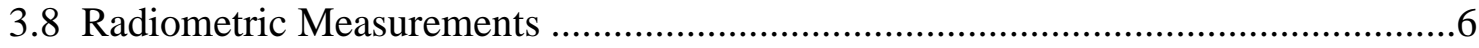

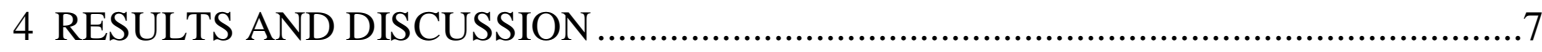

4.1 Tc-99 Langmuir Isotherm Parameters ............................................................... 7

4.2 Bed Void Fraction and Porosity.................................................................

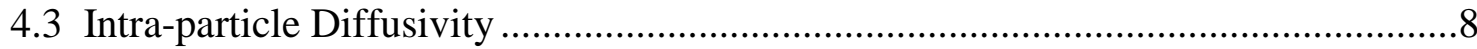

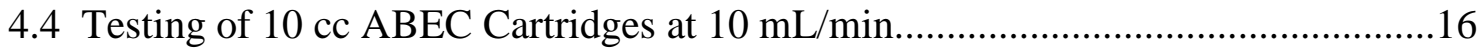

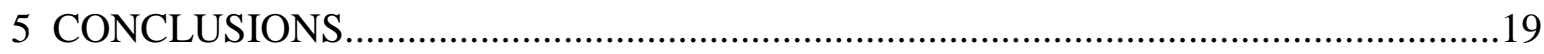

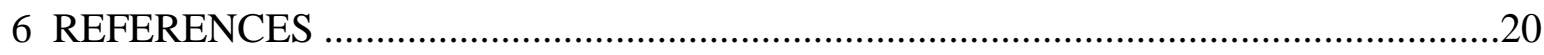

\section{FIGURES}

1 ABEC adsorption isotherm of Tc from Solution A $\left(200 \mathrm{~g} / \mathrm{L} \mathrm{Mo,} 5.1 \mathrm{M} \mathrm{K}^{+}, 1 \mathrm{M}\right.$ $\mathrm{OH}^{-}$, and $0.1 \mathrm{M} \mathrm{NO}_{3}^{-}$) at $\mathrm{RT}$.

2 ABEC adsorption isotherm of Tc from Solution B (200 g/L Mo, $9.3 \mathrm{M} \mathrm{K}^{+}, 5 \mathrm{M}$ $\mathrm{OH}^{-}$, and $0.1 \mathrm{M} \mathrm{NO}_{3}^{-}$) at $\mathrm{RT}$.

3 Experimental and VERSE simulated breakthrough curves for $2 \mathrm{cc}$ ABEC cartridges at $2 \mathrm{~mL} / \mathrm{min}$ with $0.00099 \mathrm{mM}$ Tc in Solution A. 


\section{FIGURES (Cont.)}

4 Experimental and VERSE simulated breakthrough curves for $2 \mathrm{cc}$ ABEC cartridges at $5 \mathrm{~mL} / \mathrm{min}$ with $0.00096 \mathrm{mM} \mathrm{Tc}$ in Solution A.

5 Experimental and VERSE simulated breakthrough curves for $2 \mathrm{cc}$ ABEC cartridges at $7 \mathrm{~mL} / \mathrm{min}$ with $0.00094 \mathrm{mM} \mathrm{Tc}$ in Solution A.

6 Experimental and VERSE simulated breakthrough curves for $2 \mathrm{cc}$ ABEC cartridges at $10 \mathrm{~mL} / \mathrm{min}$ with $0.0010 \mathrm{mM} \mathrm{Tc}$ in Solution A.

7 Experimental and VERSE simulated breakthrough curves for $2 \mathrm{cc}$ ABEC cartridges at $15 \mathrm{~mL} / \mathrm{min}$ with $0.0011 \mathrm{mM} \mathrm{Tc}$ in Solution A.

8 Experimental and VERSE simulated breakthrough curves for $2 \mathrm{cc}$ ABEC cartridges at $20 \mathrm{~mL} / \mathrm{min}$ with $0.0011 \mathrm{mM} \mathrm{Tc}$ in Solution A.

9 Experimental and VERSE simulated breakthrough curves for $10 \mathrm{cc}$ ABEC cartridges at 10, 20, and $30 \mathrm{~mL} / \mathrm{min}$ for $0.001 \mathrm{mM} \mathrm{Tc}$ in Solution A.

10 Experimental and VERSE simulated $0.001 \mathrm{mM}$ Tc breakthrough curve for $2 \mathrm{cc}$ ABEC cartridges at $10 \mathrm{~mL} / \mathrm{min}$ in Solution B.

11 Experimental and VERSE simulated breakthrough curve for Omnifit ABEC packed column $(0.66 \mathrm{~cm}$ ID x $0.4 \mathrm{~cm}$ length) loaded with Solution B containing $0.00358 \mathrm{mM}$ Tc at $10 \mathrm{~mL} / \mathrm{min}$.

12 Experimental and VERSE simulated breakthrough curve for Omnifit ABEC packed column ( $0.66 \mathrm{~cm}$ ID x $0.8 \mathrm{~cm}$ length) loaded with Solution B containing $0.00184 \mathrm{mM}$ Tc at $10 \mathrm{~mL} / \mathrm{min}$.

13 Experimental and VERSE simulated breakthrough curves for $10 \mathrm{cc}$ ABEC cartridges with $0.001 \mathrm{mM} \mathrm{Tc}$ at $10 \mathrm{~mL} / \mathrm{min}$ in Solution A.

14 Experimental and VERSE simulated breakthrough curves for $10 \mathrm{cc}$ ABEC cartridges with $0.001 \mathrm{mM} \mathrm{Tc}$ at $10 \mathrm{~mL} / \mathrm{min}$ in Solution B

\section{TABLES}

1 Parameters used in VERSE simulations for column design

2 Langmuir "a" values for uptake of Tc from Solution A calculated from $2 \mathrm{cc}$ column breakthrough experiments at different flow rates. 


\title{
DEVELOPMENT OF ABEC COLUMN FOR SEPARATION OF TC-99 FROM NORTHSTAR DISSOLVED TARGET SOLUTION
}

\begin{abstract}
Batch and column breakthrough experiments were performed to determine isotherms and mass-transfer parameters for adsorption of Tc on aqueous biphasic extraction chromatographic (ABEC) sorbent in two solutions: $200 \mathrm{~g} / \mathrm{L} \mathrm{Mo}$, $5.1 \mathrm{M} \mathrm{K}^{+}, 1 \mathrm{M} \mathrm{OH}^{-}$, and $0.1 \mathrm{M} \mathrm{NO}_{3}{ }^{-}$(Solution A) and $200 \mathrm{~g} / \mathrm{L} \mathrm{Mo,} 9.3 \mathrm{M} \mathrm{K}^{+}$, $5 \mathrm{M} \mathrm{OH}^{-}$, and $0.1 \mathrm{M} \mathrm{NO}_{3}{ }^{-}$(Solution $\mathrm{B}$ ). Good agreement was found between the isotherm values obtained by batch and column breakthrough studies for both Solutions A and B. Potassium-pertechnetate intra-particle diffusivity on ABEC resin was estimated by VERSE simulations, and good agreement was found among a series of column-breakthrough experiments at varying flow velocities, column sizes, and technetium concentrations. However, testing of $10 \mathrm{cc}$ cartridges provided by NorthStar with Solutions A and B did not give satisfactory results, as significant Tc breakthrough was observed and ABEC cartridge performance varied widely among experiments. These different experimental results are believed to be due to inconsistent preparation of the ABEC resin prior to packing and/or inconsistent packing.
\end{abstract}




\section{INTRODUCTION}

NorthStar Medical Radioisotopes is pursuing a neutron capture $\left[{ }^{98} \mathrm{Mo}(\mathrm{n}, \gamma){ }^{99} \mathrm{Mo}\right]$ route for ${ }^{99}$ Mo production at the University of Missouri Research Reactor (MURR). Argonne is assisting NorthStar in the development of some aspects of the operation. Once the molybdenum targets are removed from the reactor, they will undergo dissolution. The output of the dissolution results in $\sim 1500 \mathrm{~mL}$ of a $200 \mathrm{~g} / \mathrm{L} \mathrm{Mo}, 9.3 \mathrm{M} \mathrm{K}^{+}, 5 \mathrm{M} \mathrm{OH}^{-}, 0.1 \mathrm{M} \mathrm{NO}_{3}{ }^{-}$solution containing $\sim 400 \mathrm{Ci}$ of Mo-99, as well as a few other irradiation byproducts, including Tc-99. The solution is pumped from a shielded cask through a chromatography column containing ABEC to remove unwanted Tc present from the target irradiation. This polishing step allows radiopharmacies to use the first aliquot of Tc-99m they elute from their generators. Currently, radiopharmacies discard the first aliquot from the generator, as it contains unacceptable levels of Tc-99. Various ABEC cartridge sizes and flow rates have been tested to optimize the separation of Tc-99 from Mo-99. The results of those experiments along with additional batch and breakthrough experiments were utilized to determine intrinsic parameters, mass transfer, and system parameters for design of a Tc-99 separation process from the irradiated Mo target solution. The ABEC resin consists of polyethylene glycols (PEGs) physisorbed to a $2 \%$ crosslinked styrene divinylbenzene copolymer lattice. The amount of resin crosslinkage determines the bead pore size. Therefore, a resin with a lower percentage (2\%) of crosslinkage has a more open structure that is permeable to higher molecular-weight substances than a highly crosslinked resin. It also has a lower physical resistance to shrinking and swelling, so it absorbs more water and swells to a larger wet diameter than a highly crosslinked resin of equivalent dry diameter. Therefore, while the kinetics of adsorption on a low crosslinked resin may be superior, consistent packing and channeling may become a challenge in designing a commercial process. The ABEC mode uses high ionic strength salt solutions as mobile phases. In the presence of water-structuring anion salts (e.g., $\left.\mathrm{SO}_{4}{ }^{2-}, \mathrm{OH}^{-}\right)$, chaotropic ion salts $\left(\mathrm{KTcO}_{4}\right)$ are retained in the sorbent. Stripping is accomplished by washing with water by lowering the ionic strength of the aqueous phase. ${ }^{1-4}$ 


\section{THEORY}

\subsection{VERSATILE REACTION-SEPARATION (VERSE) MODEL}

The VERSE model and related simulations were developed by Wang and associates in 1991. ${ }^{5}$ The general VERSE model takes into account detailed intrinsic (scale independent) parameters, which include the system parameters (particle porosity and bed void fraction), adsorption isotherms, Brownian diffusivities, intra-particle pore diffusivities, axial dispersion coefficient, film mass transfer coefficient, mass-transfer effects, slow adsorption and desorption, ${ }^{6}$ and possible chemical reactions in the mobile phase or in the solid phase during the separations. ${ }^{7-10}$ Although the general VERSE model can take into account parallel intra-particle pore and surface diffusion, previous studies have shown that at a relatively low concentration region, effects of surface diffusion on frontal or elution chromatography cannot be distinguished from those of pore diffusion. As a result, a pore-diffusion model can be used to predict closely the frontal curves. ${ }^{11,12}$ Since the Tc-99 feed concentration in the system of interest is relatively low $\left(\sim 10^{-6} \mathrm{M}\right)$, the pore-diffusion model was tested for process simulation and design. The assumptions and equations for the pore-diffusion VERSE model have been reported elsewhere. ${ }^{5}$

\subsection{LANGMUIR ADSORPTION ISOTHERM MODEL}

When adsorption and desorption rates are much higher than the mass transfer rates, the concentrations in the solid phase and in the solution phase are at equilibrium. Under such conditions, the local solid-phase concentrations are related to the local solution-phase concentrations by an equilibrium isotherm at a given temperature. The Langmuir adsorption isotherm equation used in this study is:

$$
\mathrm{q}_{\mathrm{i}}=\frac{\mathrm{a}_{\mathrm{i}} \mathrm{C}_{\mathrm{i}}}{1+\mathrm{b}_{\mathrm{i}} \mathrm{C}_{\mathrm{i}}}
$$

where $a_{i}$ and $b_{i}$ are the Langmuir isotherm parameters of species $i$, and $q_{i}$ is the solid phase concentration of species $i$ in equilibrium with the solution phase concentration $C_{i}$. In this study, the unit of $\mathrm{C}_{\mathrm{i}}$ is $\mathrm{mmol} / \mathrm{L}$ solution, and the unit of $\mathrm{q}_{\mathrm{i}}$ is mmol/L column packing volume.

If $\mathrm{bC} \sim 1$ or $\mathrm{bC}>>1$, the relation between $\mathrm{q}$ and $\mathrm{C}$ is nonlinear, and the concentration is defined to be in the nonlinear isotherm region. If $\mathrm{bC}<<1$ or $\mathrm{q} \approx \mathrm{aC}$, the concentration in the solution is in the linear isotherm region. The metal ion concentration in the solid phase in equilibrium with the final concentration in the solution can be calculated as follows:

$$
\mathrm{q}=\frac{\left(\mathrm{C}_{0}-\mathrm{C}_{\mathrm{s}}\right) \mathrm{V}}{\mathrm{W}} \rho_{\text {packing }}
$$

where $\mathrm{C}_{0}$ is the initial Tc-99 concentration in the solution, $\mathrm{C}_{\mathrm{s}}$ is the final concentration in the solution, and $\mathrm{q}$ is the Tc-99 concentration in the solid phase in equilibrium with the final 
concentration in the solution. Also, $\mathrm{V}$ is the volume of the solution, $\mathrm{W}$ is the weight of dry sorbent, and $\rho_{\text {packing }}$ is the packing density of the sorbent, which is defined as the ratio of the sorbent dry weight to the packing volume. Thus, the unit of $\mathrm{q}$ is $\mathrm{mmol} / \mathrm{L}$ packing volume. The ABEC packing density, $\rho_{\text {packing, }}$, is $1000 \mathrm{~g} / \mathrm{L}$ for Solution A and $1300 \mathrm{~g} / \mathrm{L}$ for Solution B.

\subsection{INTRA-PARTICLE PORE DIFFUSIVITY AND EFFECTIVE CAPACITY}

Breakthrough curves for Tc-99 concentration in solution over time result from convection, diffusion, and adsorption effects. The shapes of the curves are affected by the system parameters (column length, particle size, and void fractions), operating conditions (linear velocity and temperature), and the intrinsic parameters (equilibrium adsorption isotherm and mass transfer parameters). Breakthrough curves are useful for verifying the effective column capacity at a given feed concentration ( $q$ at $C_{f}$ ) predicted with the isotherms obtained from the batch tests. The key mass transfer parameter $D_{p}$ (intra-particle diffusivity of Tc-99) can be estimated by fitting the experimental $T c$ frontal curves to the simulation results. The value of $D_{p}$ is a function of temperature, sorbent pore structure, and viscosity of the mobile phase. The sorbent capacity at the feed concentration can be calculated from the equation:

$$
q_{f}=\frac{C_{f} V_{\text {center }}}{V_{\text {column }}}
$$

where $V_{\text {center }}$ is the volume of feed solution at the center of the breakthrough curve $\left(C_{b r} / C_{f}=0.5\right)$, $\mathrm{V}_{\text {column }}$ is the volume of the column, $\mathrm{q}_{\mathrm{f}}$ is the amount of Tc adsorbed per packing volume of sorbent ( $\mathrm{mmol} / \mathrm{LCV})$, and $\mathrm{C}_{\mathrm{f}}$ is the Tc concentration in the feed solution (mM). 


\section{EXPERIMENAL}

\subsection{MATERIALS}

An ABEC sorbent with particle size of 125-250 $\mu \mathrm{m}$ was obtained from NorthStar and produced by Eichrom Technologies (Lisle, IL). Eichrom pre-packed ABEC 2 cc cartridges (ID, 0.88-0.96 cm; average ID, $0.92 \mathrm{~cm}$; column length, $2.5 \mathrm{~cm}$; and average bed height, $2.125 \mathrm{~cm}$ ). In addition, NorthStar prepared $10 \mathrm{cc}$ ABEC cartridges (ID, $1.5 \mathrm{~cm}$; length, $6 \mathrm{~cm}$ ). American Chemical Society (ACS) reagent-grade potassium hydroxide pellets and potassium nitrate crystals were used, as was ACS reagent-grade molybdenum trioxide available from Acros Organics. Ultima Gold XR liquid scintillation cocktail was obtained from Perkin Elmer. Tc-99 was original in the ammonium pertechnetate chemical form and was obtained from Oak Ridge National Laboratory. Omnitfit columns were packed with ABEC resin at Argonne, as described below.

\subsection{SOLUTION PREPARATION}

Solution A contained $200 \mathrm{~g} / \mathrm{L} \mathrm{Mo,} 5.1 \mathrm{M} \mathrm{K}^{+}, 1 \mathrm{M} \mathrm{OH}^{-}$, and $0.1 \mathrm{M} \mathrm{NO}_{3}{ }^{-}$in $18 \mathrm{M} \Omega$ deionized distilled (DI) water that had been filtered through a $0.22 \mu \mathrm{m}$ polyethersulfone (PES) filter available through Fisher Scientific. Subsequently, Tc-99 was added to the Mo solution. An aliquot of this sample was taken for liquid scintillation counting (LSC) as a baseline for the starting solution. It is expected that $170 \mu \mathrm{g}$ Tc dissolved in $1.5 \mathrm{~L}$ of feed solution is the upper limit of Tc in an irradiated natural molybdenum target.

Solution B was prepared in the same way and contained $200 \mathrm{~g} / \mathrm{L} \mathrm{Mo,} 9.3 \mathrm{M} \mathrm{K}^{+}$, $5 \mathrm{M} \mathrm{OH}^{-}, 0.1 \mathrm{M} \mathrm{NO}_{3}^{-}$, and Tc-99.

\subsection{EQUIPMENT}

ABEC cartridges were tested on a dispensing unit developed by NorthStar Medical Radioisotopes. The ABEC-packed Omnifit chromatography columns were tested with an AKTA Purifier unit (GE Healthcare, Piscataway, NJ). All column experiments were conducted at room temperature.

\subsection{VISCOSITY}

The kinematic viscosity of Solutions A and B was determined in triplicate using a Cross Arm Viscometer from Technical Glass Products, Inc. At room temperature $\left(21.4^{\circ} \mathrm{C}\right)$ the viscosity was $0.94 \mathrm{cP}$ for DI water, $1.77 \mathrm{cP}$ for Solution A, and $4.08 \mathrm{cP}$ for Solution B. 


\subsection{BATCH EQUILIBRIUM TESTS}

The uptake of Tc was determined by contacting $1 \mathrm{~mL}$ of Solution A or B containing Tc-99 with a known amount (10 $\pm 1 \mathrm{mg})$ of sorbent for $30 \mathrm{~min}$ at room temperature. After equilibration, the solution was withdrawn and filtered by using a syringe fitted with a PVDF (polyvinylidene fluoride) membrane filter (Millipore, $0.22 \mu \mathrm{m}$ pore size). Blank experiments demonstrated that the filter does not uptake Tc.

\subsection{OMNIFIT COLUMN PACKING}

For a given column size, the amount of sorbent was weighed and placed in a beaker. Water was added to the sorbent to form a $20 \%$ (v/v) slurry. The slurry was agitated at $1000 \mathrm{rpm}$ for 3 min to remove air from the sorbent and any impurities which are soluble in water. After the sorbent settled, the excess liquid was decanted. The rinsing and decanting steps were repeated two more times. The slurry was uniformly mixed and poured into the column. Water was pumped downward through the packed bed at a flow rate of $10 \mathrm{~mL} / \mathrm{min}$ for $30 \mathrm{~min}$. Ten bed volumes of $5 \mathrm{M} \mathrm{KOH}$ solution were pumped downward through the packed bed at a flow rate of $10 \mathrm{~mL} / \mathrm{min}$. The adjuster was lowered to the surface of sorbent layer and then tightened.

\subsection{COLUMN EXPERIMENTS}

The ABEC cartridges were tested with a dispensing unit developed by NorthStar Medical Radioisotopes. The dispensing unit uses pressure to push eluents through the ABEC column. The column was conditioned with $\sim 10$ bed volumes of $5 \mathrm{M} \mathrm{KOH}$. After conditioning, an aliquot of $29 \mathrm{~mL}$ of Solution A or B, containing Tc-99, was passed through the ABEC cartridge, and a sample was collected for LSC. Either 5 or 50 aliquots were passed through the column, depending upon the experiment. After passing the appropriate number of aliquots through the column, the column was stripped of Tc using $18 \mathrm{M} \Omega$ deionized water. The ABEC packed Omnifit columns were tested with an AKTA Purifier Unit. The columns were pre-equilibrated with 10 bed volumes of $5 \mathrm{M} \mathrm{KOH}$, feed solution was loaded at $10 \mathrm{~mL} / \mathrm{min}$, and aliquots were collected and sampled.

\subsection{RADIOMETRIC MEASUREMENTS}

The Tc-99 activity was quantified by measuring its $\alpha$-emission on a Perkin-Elmer liquid scintillation counter, and the amount of Tc-99 was calculated by using a calibration curve. 


\section{RESULTS AND DISCUSSION}

\subsection{Tc-99 LANGMUIR ISOTHERM PARAMETERS}

Figures 1 and 2 show the absorption isotherms for ABEC uptake of Tc-99 from Solutions $\mathrm{A}$ and $\mathrm{B}$ at room temperature (RT). The data points were obtained via batch adsorption equilibrium tests calculated using Eq. (2). The Langmuir isotherm model, Eq. (1), was applied to fit the data using the nonlinear analysis tool in Origin 2015. The best fitting of the data indicates that at RT for Solution A, the Tc Langmuir isotherm "a" = $113 \mathrm{~L}$ solution volume/L packing volume and "b" =0 (Figure 1). In Solution B at RT, the Tc Langmuir isotherm constant is nearly an order of magnitude higher, "a" $=970$ and " $b "=0$ (Figure 2). The driving force for higher Tc extraction from Solution B is the higher ionic strength of as well as increased concentration of $\mathrm{K}^{+}$, which coextracts with $\mathrm{TcO}_{4}{ }^{-}$and facilitates uptake on the resin.

\subsection{BED VOID FRACTION AND POROSITY}

Bed void fraction $\varepsilon_{\mathrm{b}}=0.3$ was determined empirically. Porosity was calculated by assuming the total void fraction $\varepsilon_{\mathrm{t}}=0.6$. That value was substituted into $\varepsilon_{\mathrm{p}}=\left(\varepsilon_{\mathrm{t}}-\varepsilon_{\mathrm{b}}\right) /\left(1-\varepsilon_{\mathrm{b}}\right)$, and yielded $\varepsilon_{\mathrm{p}}=0.4$. While those numbers are used in VERSE simulations, it needs to be noted that the volume of the stationary phase changes with solution composition and during column loading. Therefore, these numbers may introduce a systematic error and should be treated as arbitrary.

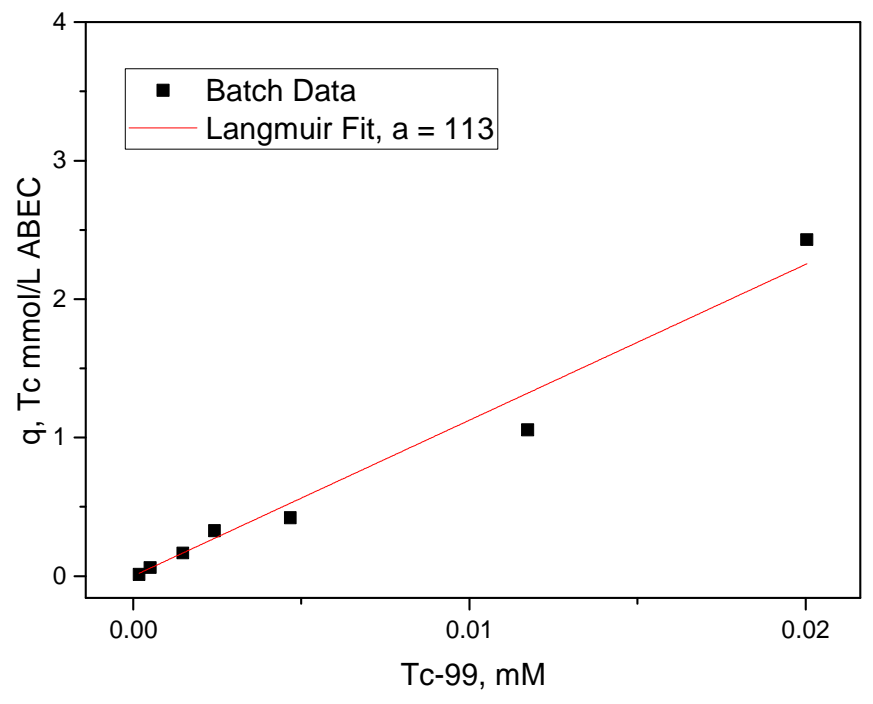

FIGURE 1 ABEC adsorption isotherm of Tc from Solution A (200 g/L Mo, 5.1 M K', 1 M OH; and $0.1 \mathrm{M} \mathrm{NO}_{3}{ }^{-}$) at RT. 


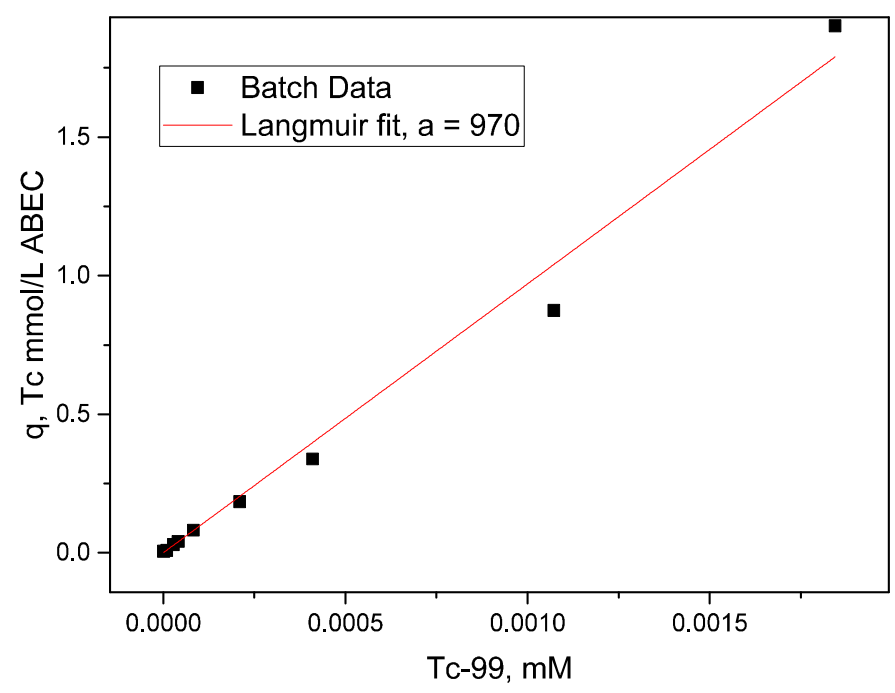

FIGURE 2 ABEC adsorption isotherm of Tc from Solution B $\left(200 \mathrm{~g} / \mathrm{L} \mathrm{Mo,} \mathrm{9.3} \mathrm{M} \mathrm{K}^{+}, 5 \mathrm{M} \mathrm{OH}^{-}\right.$, and $0.1 \mathrm{M} \mathrm{NO}_{3}^{-}$) at RT.

\subsection{INTRA-PARTICLE DIFFUSIVITY}

Brownian diffusivity $\left(\mathrm{D}_{\mathrm{b}}\right)$ of $\mathrm{TcO}_{4}{ }^{-}$in water at $25^{\circ} \mathrm{C}$ is reported to be $1.17 \times 10^{-3}$ $\mathrm{cm}^{2} / \mathrm{min} .{ }^{13}$ The Stokes-Einstein equation was used to correct for viscosity and temperature effects. The result shows that $\mathrm{D}_{\mathrm{b}}=5.86 \times 10^{-4} \mathrm{~cm}^{2} / \mathrm{min}$ and $2.54 \times 10^{-4} \mathrm{~cm}^{2} / \mathrm{min}$ at RT for Tc in Solutions A and B, respectively. Figures 3-8 present VERSE simulated breakthrough curves along with experimental data obtained from the 2 cc ABEC cartridges in solution $\mathrm{A}$ at flow rates of $2,5,7,10,15$, and $20 \mathrm{~mL} / \mathrm{min}$, using the NorthStar dispensing unit. The average Tc concentration in Solution A was $0.001 \mathrm{mM}$.

The VERSE simulations were used to find the intra-particle diffusivity $\left(D_{p}\right)$ value that can fit the experimental breakthrough curves for $2 \mathrm{cc}$ ABEC cartridges at 2-20 $\mathrm{mL} / \mathrm{min}$. The intrinsic parameters, system parameters, and numerical parameters used in the VERSE simulations are summarized in Table 1. The best fit indicates that $D_{p}$ for ABEC Tc in Solution $A$ is $2.0 \times 10^{-3} \mathrm{~cm}^{2} / \mathrm{min}$ (from Figures 3-8). This value is higher than the $D_{b}=5.86 \times 10^{-4} \mathrm{~cm}^{2} / \mathrm{min}$ reported in the literature and adjusted for viscosity and temperature effects in Solution A. This increased diffusivity is attributed to an accelerated diffusion effect, where diffusion is increased by coupled diffusion fluxes. Coupled diffusion fluxes occur when the flux of the solute is altered by the concentration gradient of other solutes. ${ }^{14,15}$ In addition, the increased diffusivity may be caused by a higher concentration/activity of $\mathrm{K}^{+}$, which coextracts with $\mathrm{TcO}_{4}{ }^{-}$. Therefore, it is assumed that in solution $\mathrm{A}, \mathrm{Tc} \mathrm{D}_{\mathrm{p}}=\mathrm{D}_{\mathrm{b}}=2.0 \times 10^{-3} \mathrm{~cm}^{2} / \mathrm{min}$. 


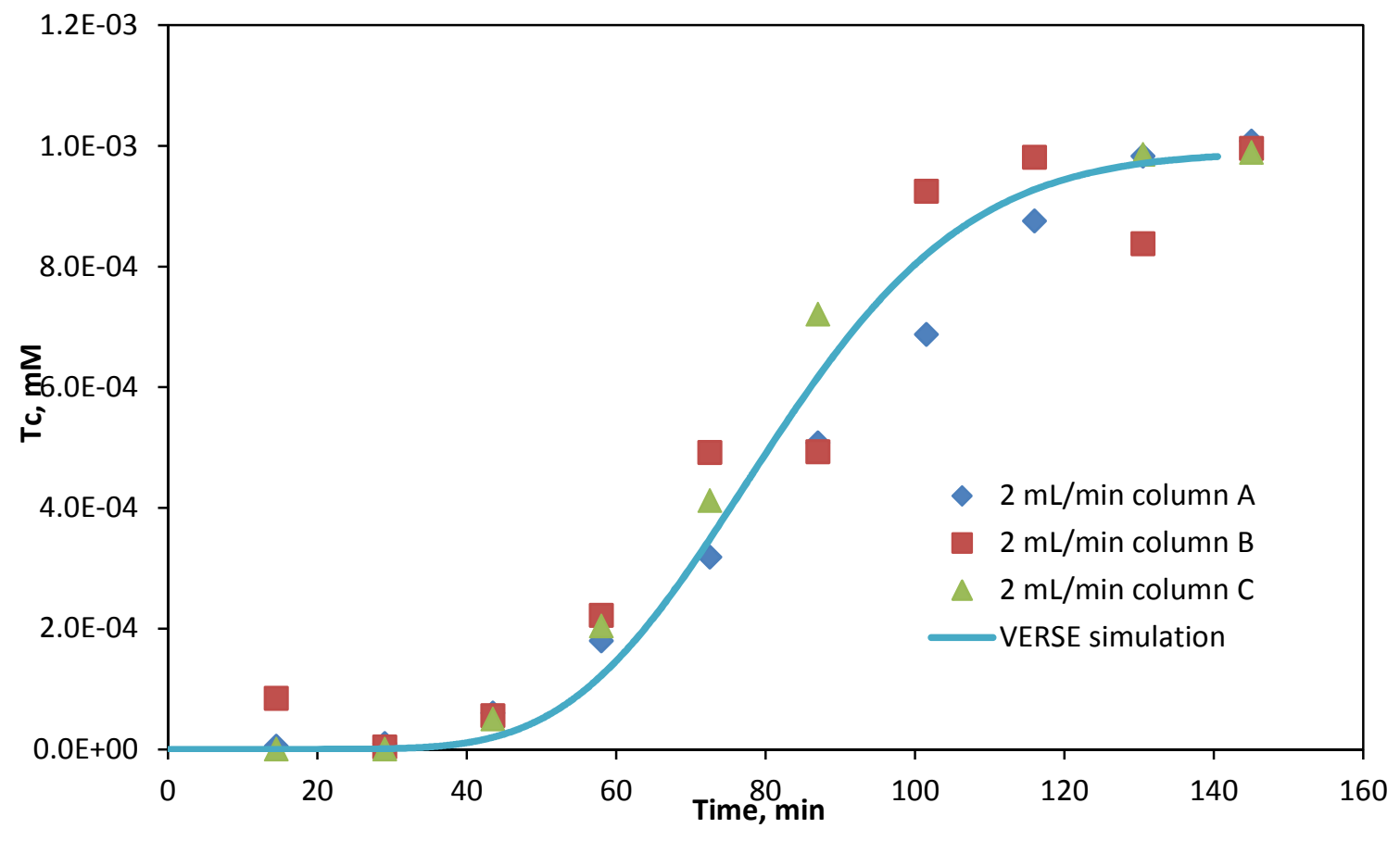

FIGURE 3 Experimental and VERSE simulated breakthrough curves for 2 cc ABEC cartridges at $2 \mathrm{~mL} / \mathrm{min}$ with $0.00099 \mathrm{mM}$ Tc in Solution A.

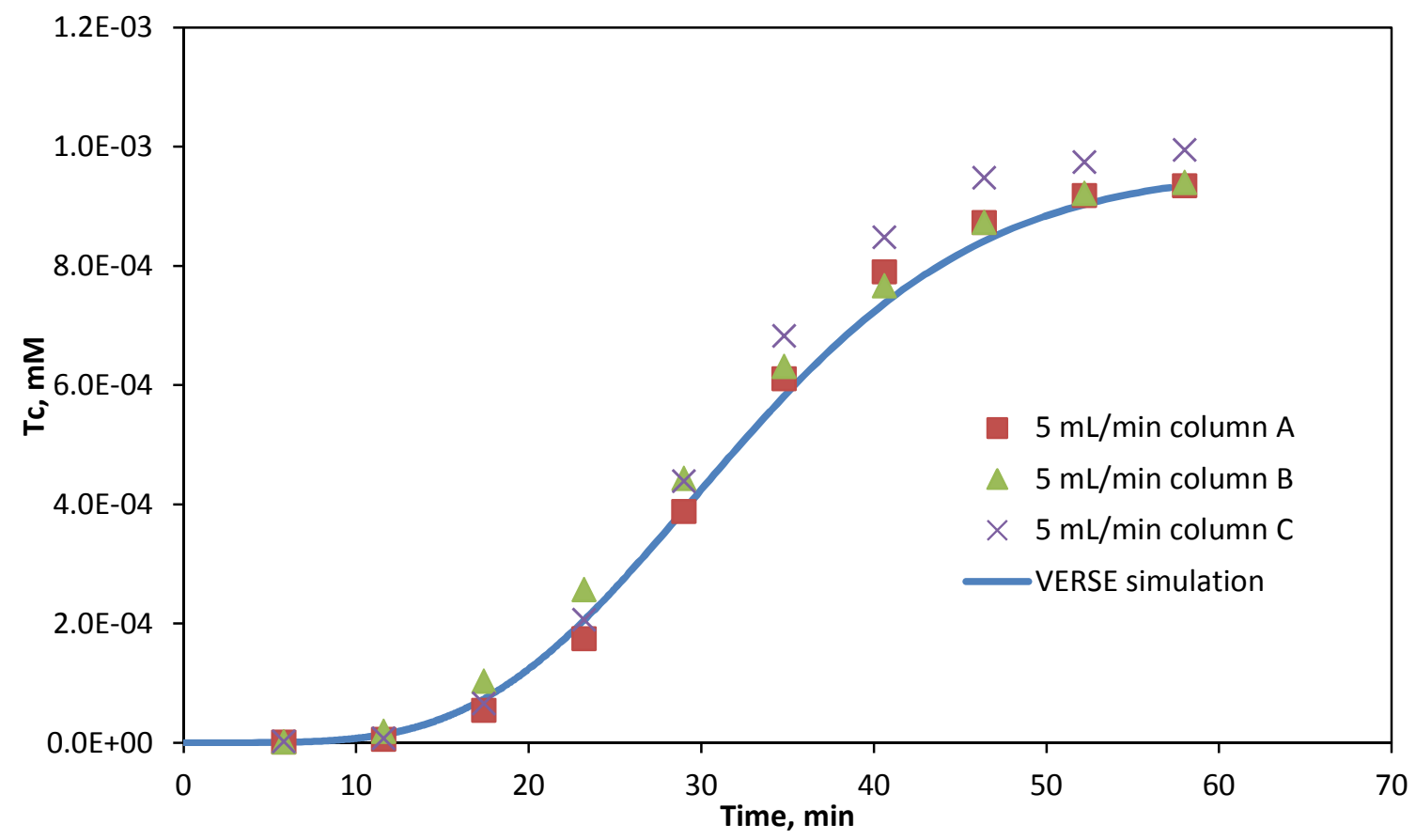

FIGURE 4 Experimental and VERSE simulated breakthrough curves for 2 cc ABEC cartridges at $5 \mathrm{~mL} / \mathrm{min}$ with $0.00096 \mathrm{mM}$ Tc in Solution A. 


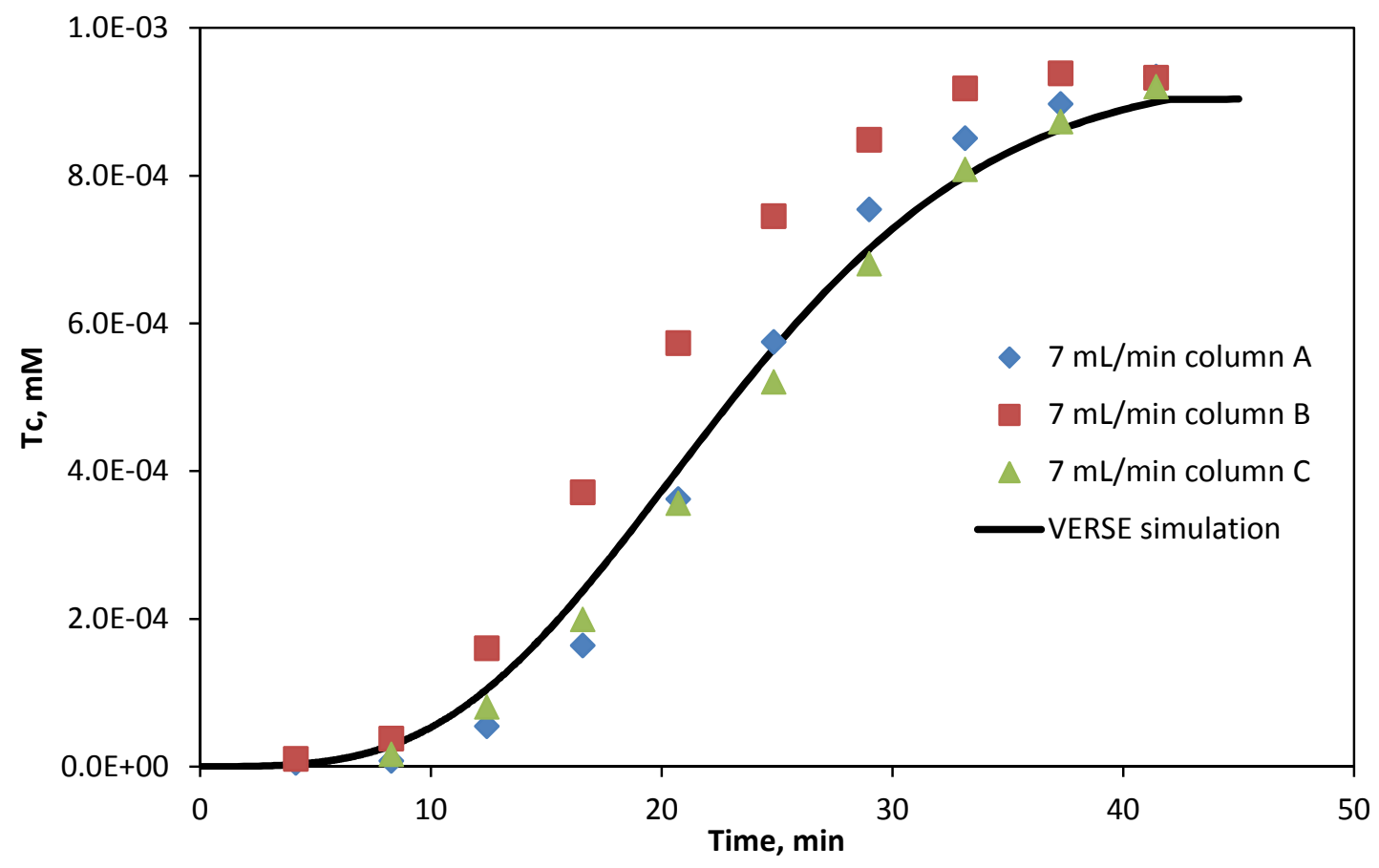

FIGURE 5 Experimental and VERSE simulated breakthrough curves for 2 cc ABEC cartridges at $7 \mathrm{~mL} / \mathrm{min}$ with $0.00094 \mathrm{mM}$ Tc in Solution A.

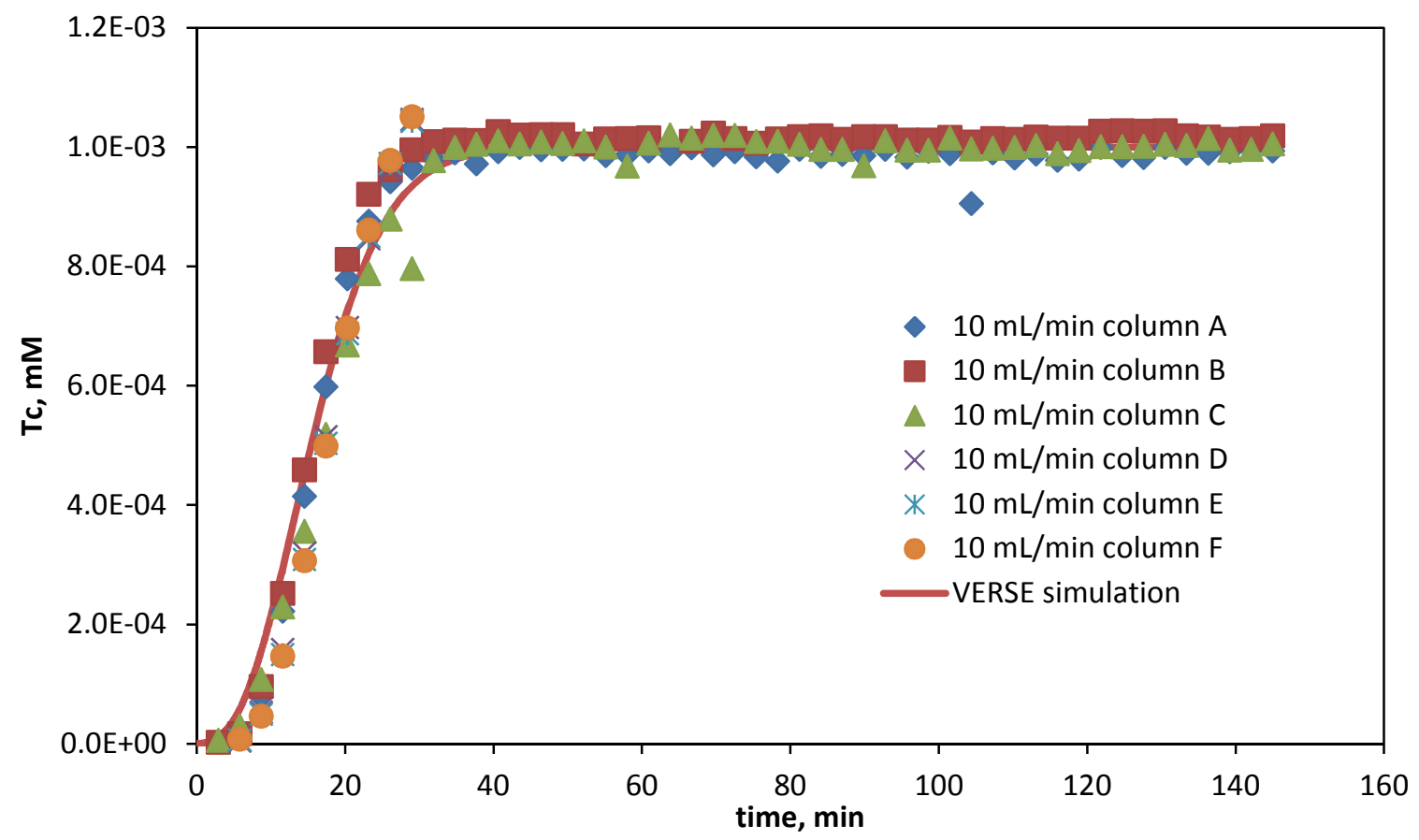

FIGURE 6 Experimental and VERSE simulated breakthrough curves for 2 cc ABEC cartridges at $10 \mathrm{~mL} / \mathrm{min}$ with $0.0010 \mathrm{mM}$ Tc in Solution A. 


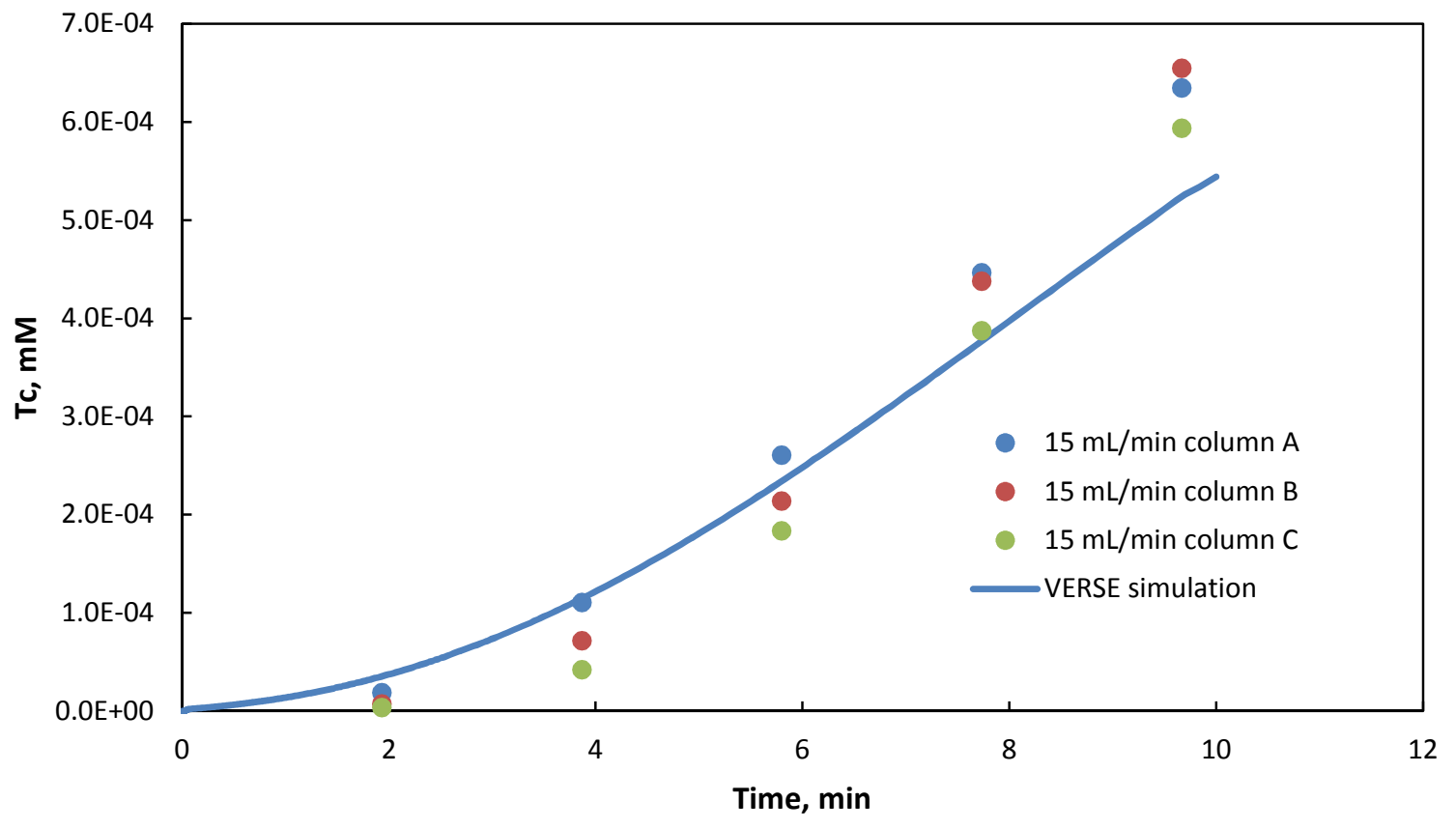

FIGURE 7 Experimental and VERSE simulated breakthrough curves for 2 cc ABEC cartridges at $15 \mathrm{~mL} / \mathrm{min}$ with $0.0011 \mathrm{mM}$ Tc in Solution A.

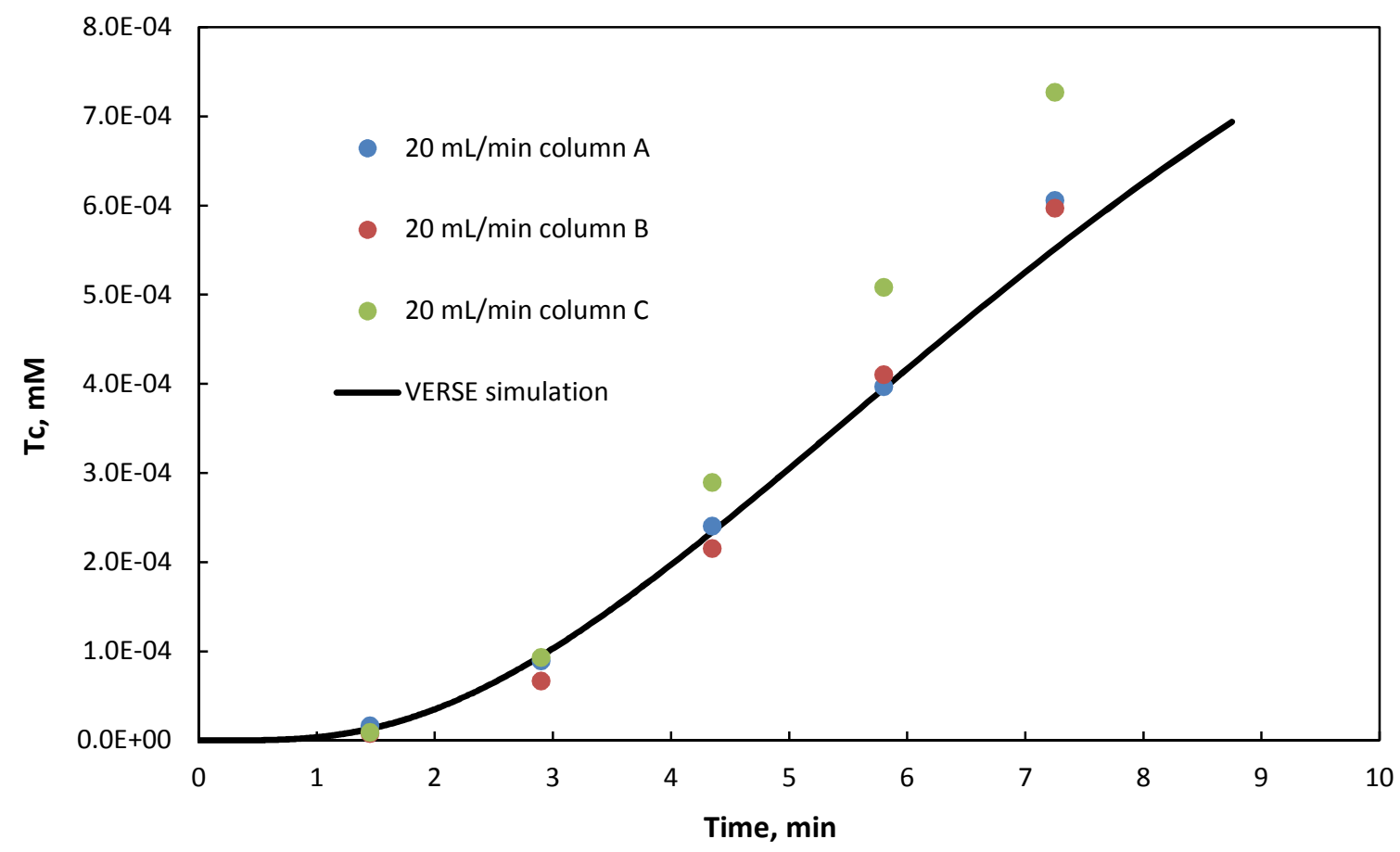

FIGURE 8 Experimental and VERSE simulated breakthrough curves for 2 cc ABEC cartridges at $20 \mathrm{~mL} / \mathrm{min}$ with $0.0011 \mathrm{mM}$ Tc in Solution A. 
TABLE 1 Parameters used in VERSE simulations for column design

\begin{tabular}{|c|c|c|c|c|c|}
\hline \multicolumn{6}{|c|}{ System Parameters } \\
\hline Sorbent & \multicolumn{2}{|c|}{$\mathrm{R}(\mu \mathrm{m})$} & $\varepsilon_{\mathrm{b}}$ & \multicolumn{2}{|c|}{$\varepsilon_{\mathrm{p}}$} \\
\hline $\mathrm{ABEC}$ & \multicolumn{2}{|c|}{85} & 0.3 & \multicolumn{2}{|c|}{0.4} \\
\hline \multicolumn{6}{|c|}{ Mass Transfer Parameters } \\
\hline Solution & \multicolumn{2}{|c|}{$\mathrm{D}_{\mathrm{p}}\left(\mathrm{cm}^{2} / \mathrm{min}\right)$} & $\mathrm{k}_{\mathrm{f}}(\mathrm{cm} / \mathrm{min})$ & \multicolumn{2}{|c|}{$\mathrm{E}_{\mathrm{b}}\left(\mathrm{cm}^{2} / \mathrm{min}\right)$} \\
\hline A & \multicolumn{2}{|c|}{$2.0 \times 10^{-3}$} & \multirow{2}{*}{$\begin{array}{l}\text { From Wilson and } \\
\text { Geankoplis }(1966)^{18}\end{array}$} & \multirow{2}{*}{\multicolumn{2}{|c|}{$\begin{array}{l}\text { From Chung and } \\
\text { Wen }(1968)^{19}\end{array}$}} \\
\hline $\mathrm{B}$ & $3.0 \times$ & $10^{-3}$ & & & \\
\hline \multicolumn{6}{|c|}{ Isotherm Parameters (Langmuir) } \\
\hline Solution & \multicolumn{3}{|c|}{$\mathrm{a}$} & \multicolumn{2}{|c|}{$\mathrm{b}(1 / \mathrm{mM})$} \\
\hline A & \multicolumn{3}{|c|}{113} & \multicolumn{2}{|l|}{0} \\
\hline $\mathrm{B}$ & \multicolumn{3}{|c|}{970} & \multicolumn{2}{|l|}{0} \\
\hline \multicolumn{6}{|c|}{ Numerical Parameters } \\
\hline \multirow{2}{*}{$\begin{array}{c}\text { Axial } \\
\text { Elements }\end{array}$} & \multirow{2}{*}{$\begin{array}{c}\text { Step Size } \\
\left(\mathrm{L} \varepsilon_{\mathrm{b}} / \mathrm{u}_{\mathrm{s}}\right)\end{array}$} & \multicolumn{2}{|c|}{ Collocation Points } & \multicolumn{2}{|c|}{ Tolerance } \\
\hline & & Axial & Particle & te $(\mathrm{mM})$ & Relative \\
\hline 100 & 0.01 & 4 & 4 & $0^{-7}$ & $10^{-3}$ \\
\hline
\end{tabular}

The Tc Langmuir "a" values estimated from breakthrough experiments using Eq. (3) are summarized in Table 2 and are in good agreement with Langmuir isotherm values obtained via batch adsorption equilibrium tests. The results indicate that resin utilization decreases as contact time decreases at higher flow rates. This effect can be explained by the "empty bed contact time" effect, ${ }^{16,17}$ where at short contact times $\mathrm{KTcO}_{4}$ can only diffuse into the polyethylene glycol layer grafted on the resin surface. At the same time, at short contact times, as Tc can only diffuse into the resin surface, the "apparent" $D_{p}$ increases. This is exemplified in Figure 9, where at higher flow rates, the actual breakthrough curves become sharper than the simulations. For this reason, as the contact time increases, the resin utilization increases, and the apparent $D_{p}$ decreases. The intrinsic parameters, system parameters, and numerical parameters used for the VERSE simulations in Figure 9 are summarized in Table 1.

VERSE simulations were used to find $\mathrm{D}_{\mathrm{p}}$ for ABEC Tc uptake from Solution $\mathrm{B}$ by fitting the experimental breakthrough curve for the $2 \mathrm{cc}$ ABEC cartridge at $10 \mathrm{~mL} / \mathrm{min}$. The intrinsic parameters, system parameters, and numerical parameters used in VERSE simulations are summarized in Table 1. The best fitting shows that $D_{p}$ for ABEC Tc uptake from Solution $B$ is $0.1 \mathrm{~cm}^{2} / \mathrm{min}$ (Figure 10), indicating that the Tc diffusivity in Solution B is faster than $D_{b}$ for Tc uptake from Solution A. This effect is expected due to accelerated diffusion caused by the concentration gradient of other solutes and the higher concentration/activity of $\mathrm{K}^{+} .^{14-15}$ 
TABLE 2 Langmuir "a" values for uptake of Tc from Solution A calculated from 2 cc column breakthrough experiments at different flow rates.

\begin{tabular}{cc}
\hline & $\begin{array}{c}\text { Langmuir a (avg), solution } \\
\text { volume/L packing volume }\end{array}$ \\
\hline Flow rate (mL/min) & 113 \\
2 & 108 \\
5 & 108 \\
7 & 58 \\
10 & 94 \\
15 & 93 \\
20 & \\
\hline
\end{tabular}

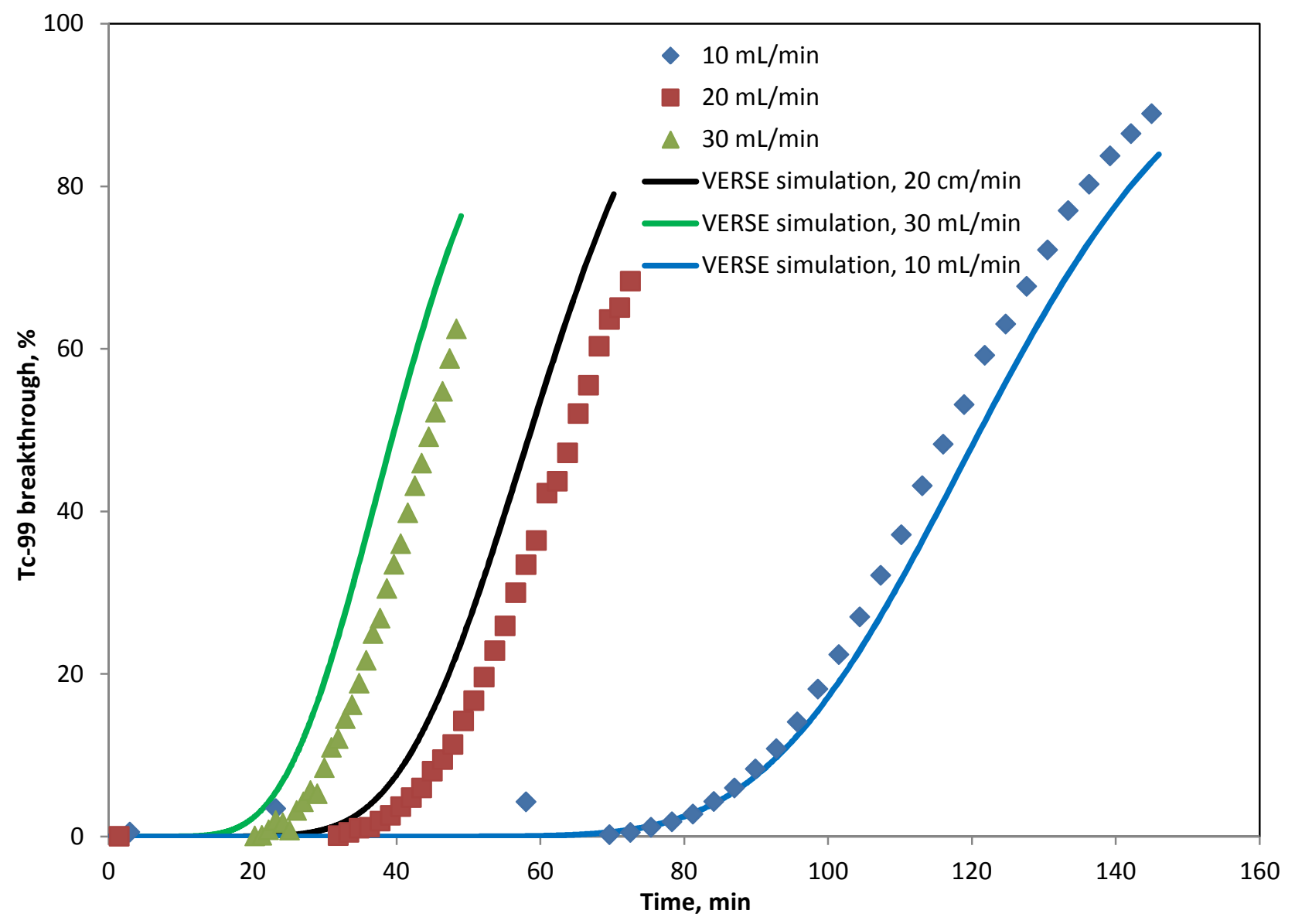

FIGURE 9 Experimental and VERSE simulated breakthrough curves for 10 cc ABEC cartridges at 10,20 , and $30 \mathrm{~mL} / \mathrm{min}$ for $0.001 \mathrm{mM}$ Tc in Solution A. 


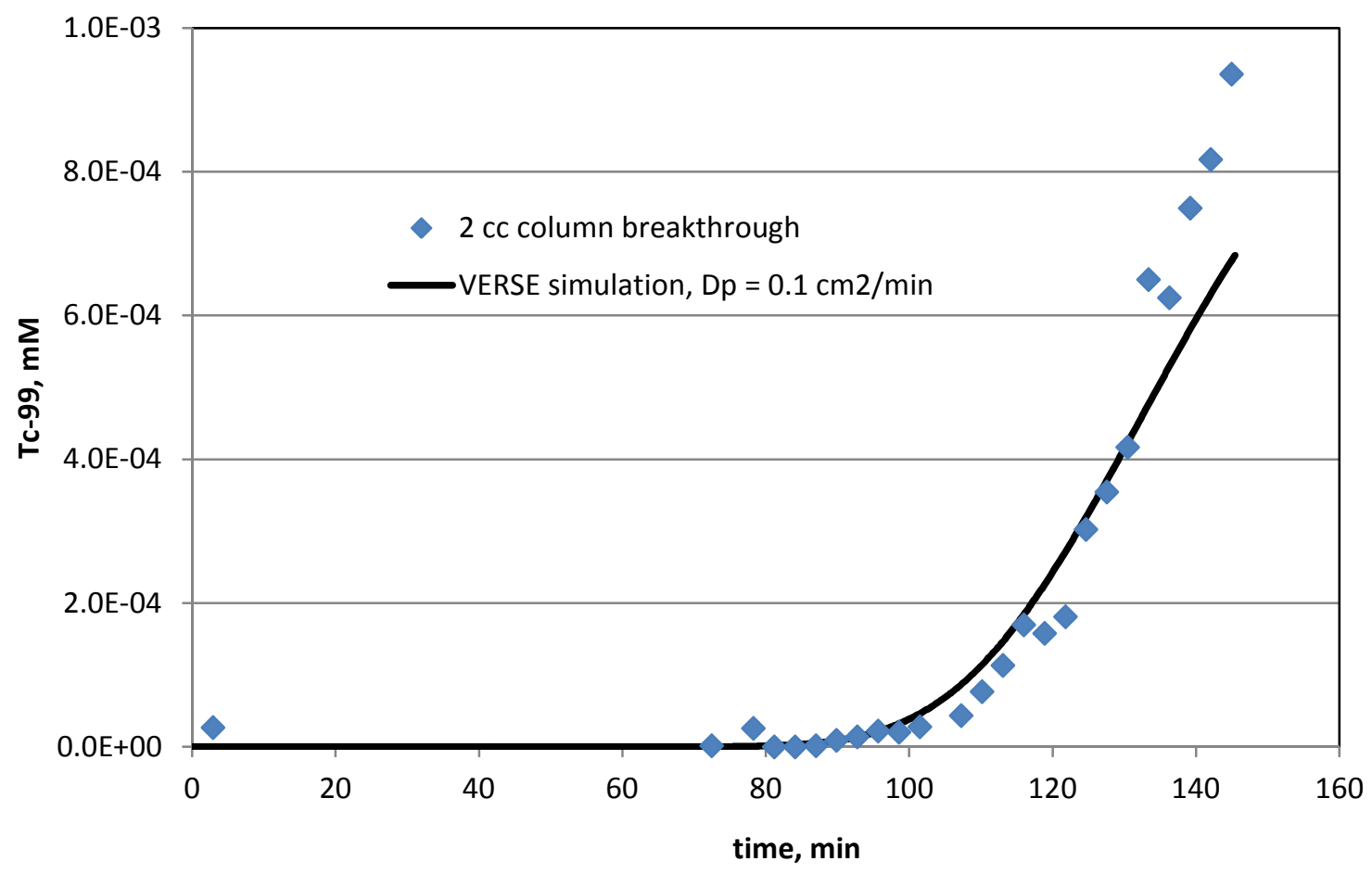

FIGURE 10 Experimental and VERSE simulated $0.001 \mathrm{mM}$ Tc breakthrough curve for 2 cc ABEC cartridges at $10 \mathrm{~mL} / \mathrm{min}$ in Solution B.

Breakthrough curves were obtained from Omnifit columns packed with ABEC sorbent using the AKTA system. Solution B containing either $0.00386 \mathrm{mM}$ Tc-99 or $0.00215 \mathrm{mM}$ Tc-99 was loaded on a column with $0.66 \mathrm{~cm}$ ID x $0.4 \mathrm{~cm}$ length or $0.66 \mathrm{~cm}$ ID x $0.8 \mathrm{~cm}$ length, respectively, and tests were run at $10 \mathrm{~mL} / \mathrm{min}$ and RT. VERSE simulations were used to find the $D_{p}$ value that fits the experimental breakthrough curves. The intrinsic parameters, system parameters, and numerical parameters used in VERSE simulations are summarized in Table 1. The best fitting indicates that the $D_{p}$ for ABEC Tc uptake in Solution B is $3.0 \times 10^{-3} \mathrm{~cm}^{2} / \mathrm{min}$ (Figures 11 and 12). This value is higher than the $D_{b}=2.0 \times 10^{-3} \mathrm{~cm}^{2} / \mathrm{min}$ for ABEC Tc uptake in Solution A. This higher value is caused by an accelerated diffusion effect, where diffusion is increased by coupled diffusion fluxes due to a higher concentration gradient of other solutes and a higher concentration of $\mathrm{K}^{+}{ }^{14,15}$ The $\mathrm{D}_{\mathrm{p}}$ for Tc in Solution B measured in those experiments is lower than that measured with the $2 \mathrm{cc}$ ABEC cartridge (Figure 10). The Tc Langmuir "a" values were estimated from the breakthrough data in Figures 11 and 12 using Eq. (3) and found to be a $=928$ and 939, respectively. These values are in good agreement with the Langmuir isotherm values obtained via batch adsorption equilibrium tests. 


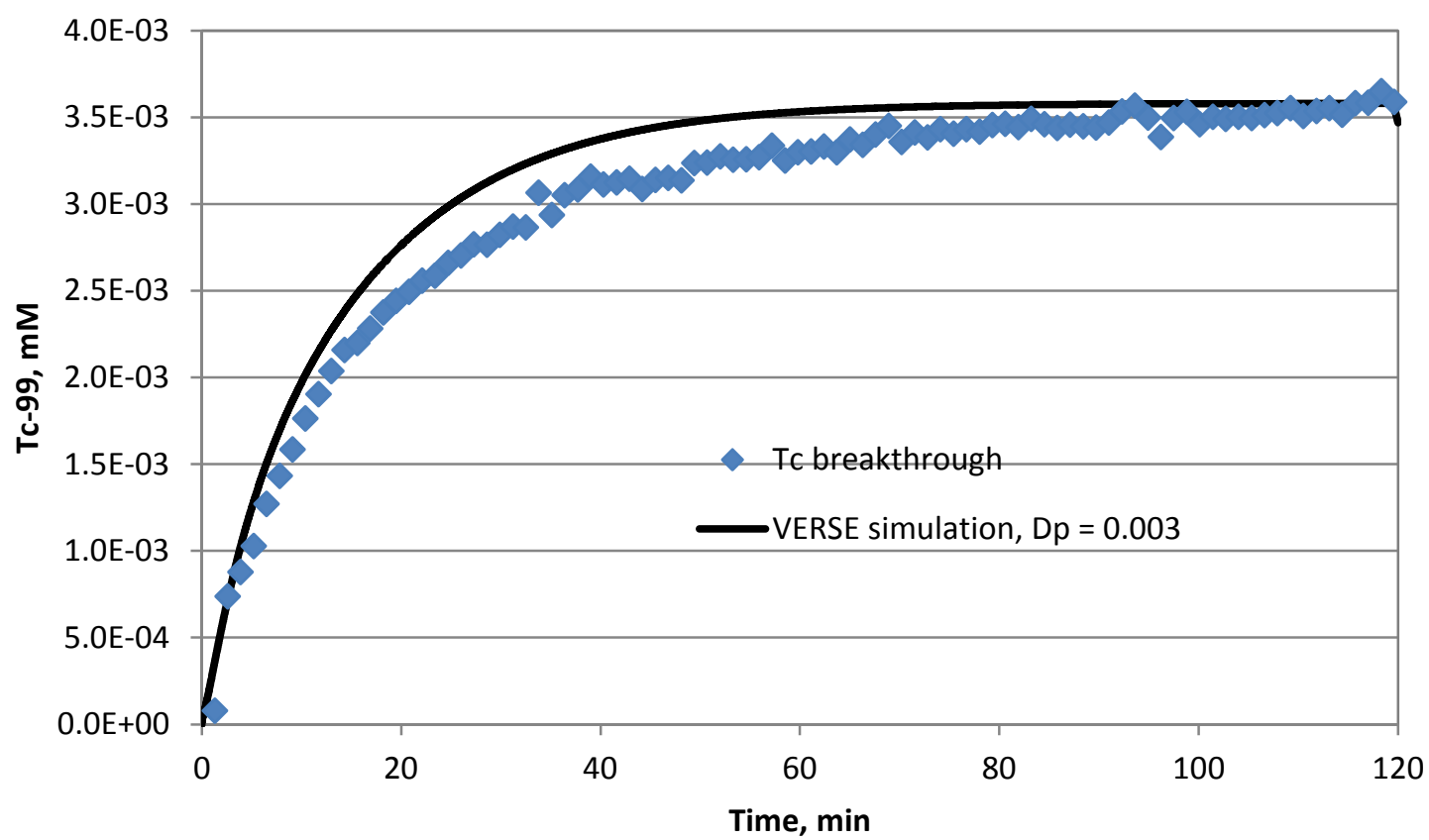

FIGURE 11 Experimental and VERSE simulated breakthrough curve for Omnifit ABEC packed column $(0.66 \mathrm{~cm}$ ID x $0.4 \mathrm{~cm}$ length) loaded with Solution B containing $0.00358 \mathrm{mM}$ Tc at $10 \mathrm{~mL} / \mathrm{min}$.

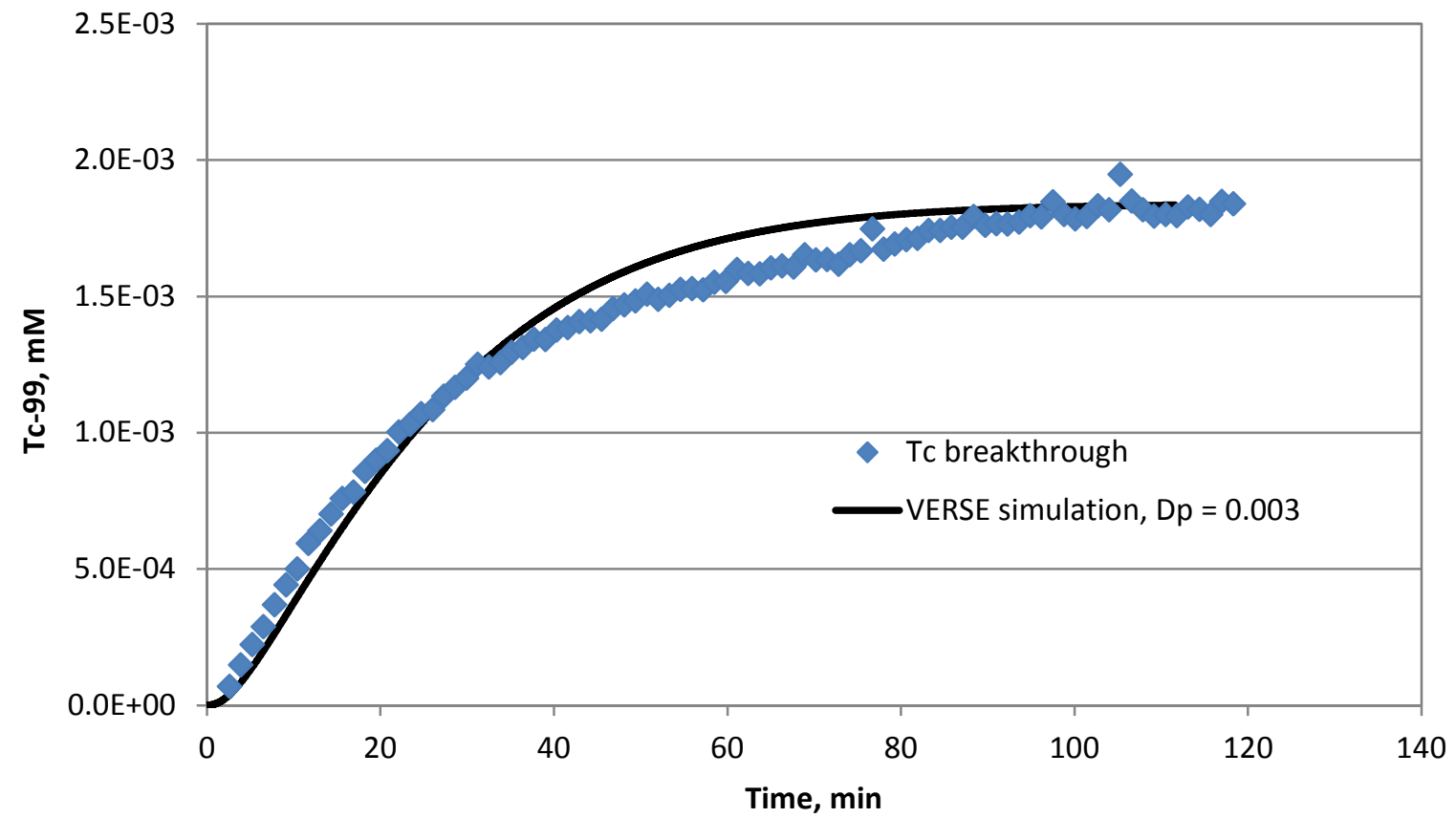

FIGURE 12 Experimental and VERSE simulated breakthrough curve for Omnifit ABEC packed column $(0.66 \mathrm{~cm}$ ID x $0.8 \mathrm{~cm}$ length) loaded with Solution B containing $0.00184 \mathrm{mM}$ Tc at $10 \mathrm{~mL} / \mathrm{min}$. 


\subsection{TESTING OF 10 CC ABEC CARTRIDGES AT 10 ML/MIN}

Twenty $10 \mathrm{~mL}$ ABEC cartridges have been tested at $10 \mathrm{~mL} / \mathrm{min}$ flow rates using Solution A containing $0.001 \mathrm{mM} \mathrm{Tc}-99$. The results of three experiments were discarded due to low concentrations of Tc-99.

Figure 13 shows the breakthrough curves for 17 ABEC cartridges. The experimental data indicate a wide array of column performances under identical experimental conditions. In addition, VERSE was used to simulate Tc breakthrough on a $10 \mathrm{cc}$ ABEC cartridge $(1.5 \mathrm{~cm}$ ID x $6 \mathrm{~cm}$ long) using the parameters summarized in Table 1. The VERSE simulated breakthrough curves predict the results of PAT 3, PAT 7, PAT 8, PAT 10 and the breakthrough experiments for New Solution Column 3. The VERSE simulation of breakthrough curves generated by reducing the bed height by $25 \%$ (to $4.5 \mathrm{~cm}$ ) or reducing the resin capacity by $25 \%$ fits the results of PAT 1, PAT 2, PAT 4, PAT 5, and New Solution Column 2, 4, and 5. Alternatively, VERSE simulation of breakthrough curves generated by increasing the bed height by $17 \%$ (to $7 \mathrm{~cm}$ ) or increasing the resin capacity by $17 \%$ fits the results of PAT 6 and PAT 9 . The inconsistent experimental results of Tc-99 uptake in Soluiton A are believed to be due to an inconsistent preparation of the $\mathrm{ABEC}$ resin prior to packing and/or inconsistent cartridge packing.

Sixteen $10 \mathrm{~mL}$ ABEC cartridges have been tested at $10 \mathrm{~mL} / \mathrm{min}$ flow rates using Solution B containing $0.001 \mathrm{mM}$ Tc-99. Figure 14 shows the breakthrough data for these ABEC cartridges. The data indicate a wide array of column performances under identical experimental conditions. In addition, VERSE was used to simulate Tc breakthrough on a $10 \mathrm{cc}$ ABEC cartridge ( $1.5 \mathrm{~cm}$ ID x $6 \mathrm{~cm}$ long) using the parameters summarized in Table 1. The VERSE simulated breakthrough curve predicts that Tc breakthrough is below detection limits. As suggested above for Solution A, the inconsistent experimental results of Tc-99 uptake in Solution $\mathrm{B}$ are believed to be due to an inconsistent preparation of the ABEC resin prior to packing and/or inconsistent cartridge packing. 


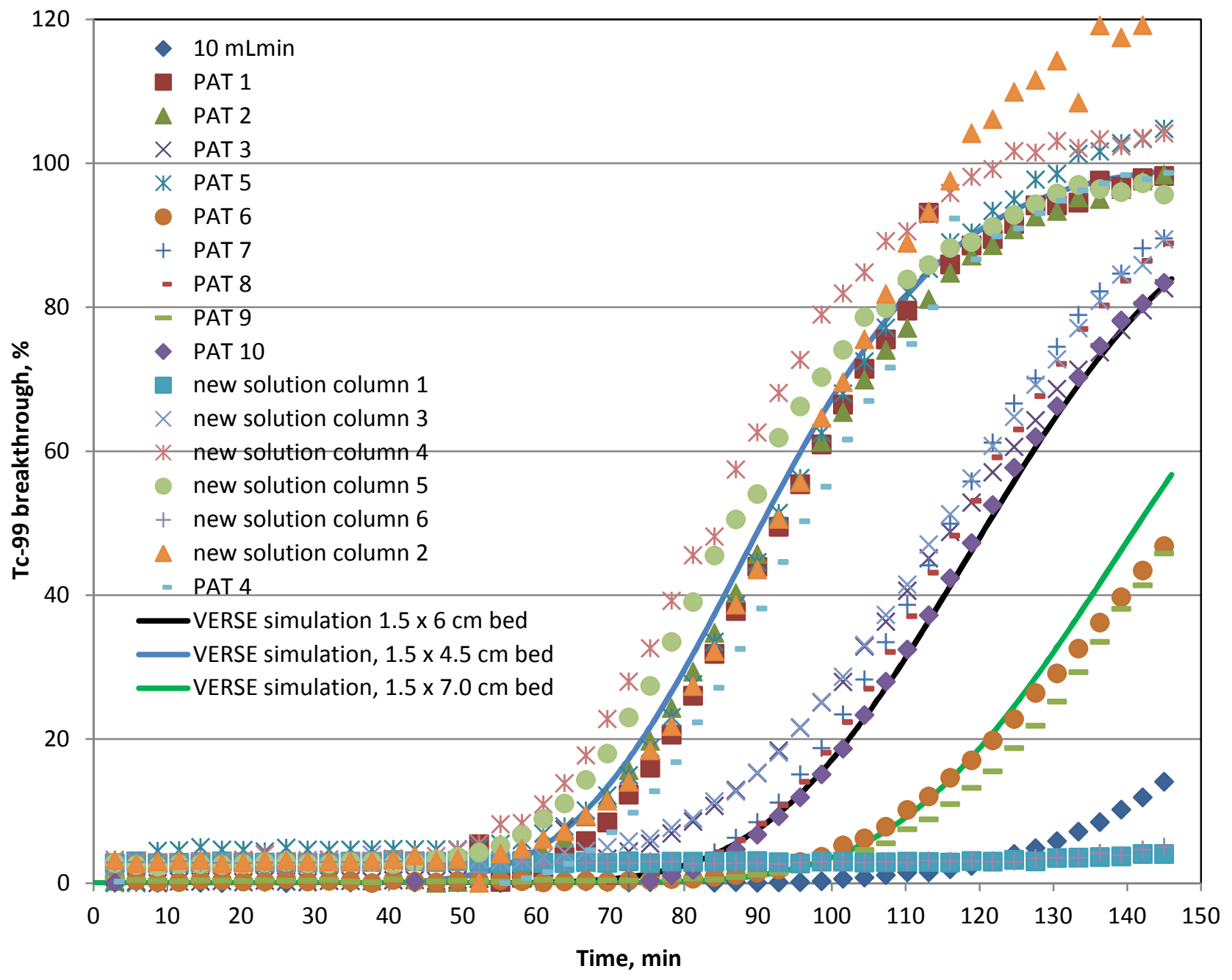

FIGURE 13 Experimental and VERSE simulated breakthrough curves for 10 cc ABEC cartridges with $0.001 \mathrm{mM}$ Tc at $10 \mathrm{~mL} / \mathrm{min}$ in Solution A. 


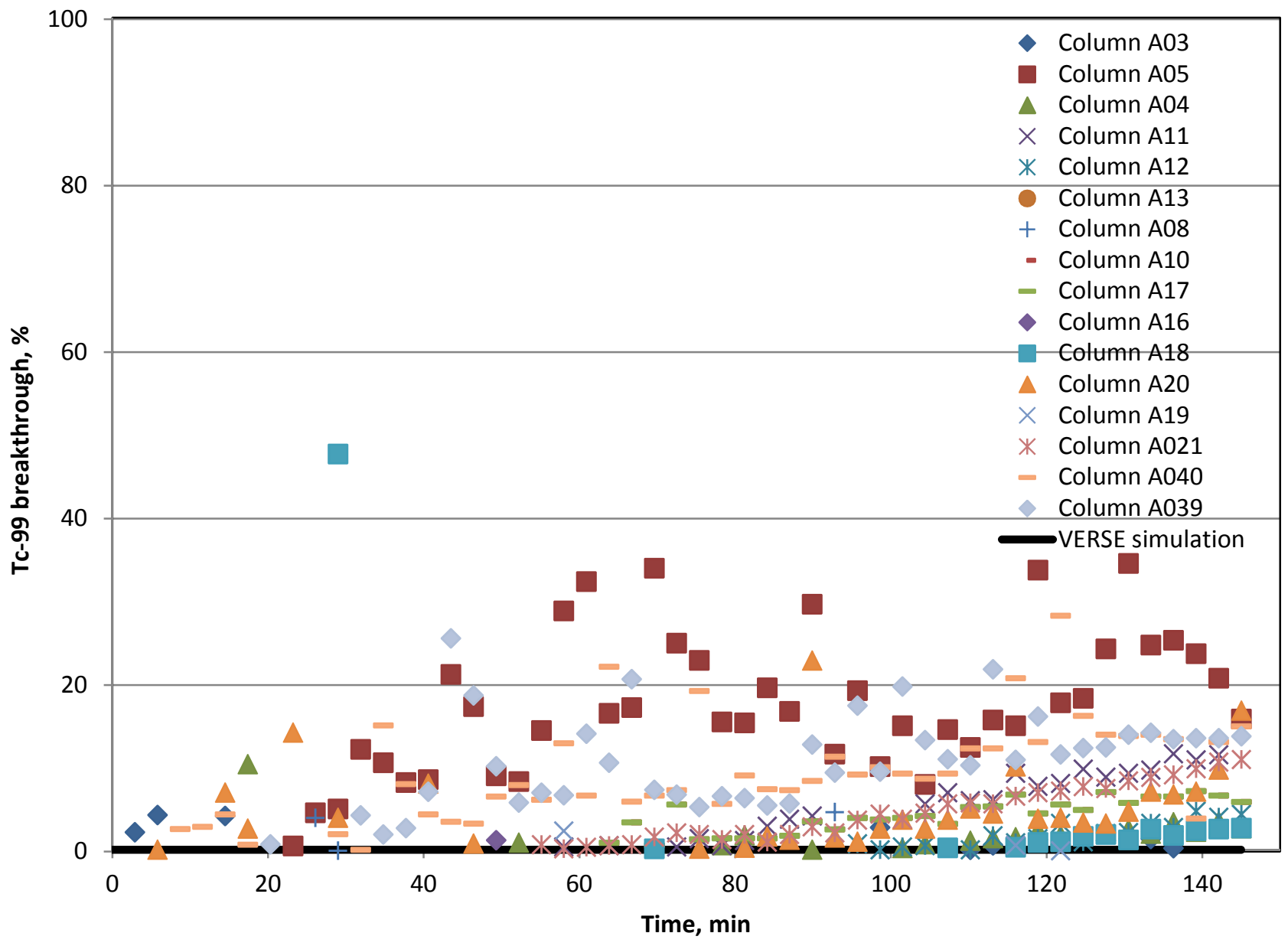

FIGURE 14 Experimental and VERSE simulated breakthrough curves for 10 cc ABEC cartridges with $0.001 \mathrm{mM}$ Tc at $10 \mathrm{~mL} / \mathrm{min}$ in Solution B. 


\section{CONCLUSIONS}

Batch and column breakthrough experiments were performed to determine isotherms and mass-transfer parameters for adsorption of Tc on the ABEC sorbent in Solution A (200 g/L Mo, 5.1 $\mathrm{M} \mathrm{K}^{+}, 1 \mathrm{M} \mathrm{OH}^{-}$, and $\left.0.1 \mathrm{M} \mathrm{NO}_{3}^{-}\right)$and Solution B (200 g/L Mo, 9.3 $\mathrm{M} \mathrm{K}^{+}, 5 \mathrm{M} \mathrm{OH}^{-}$, and $0.1 \mathrm{M} \mathrm{NO}_{3}{ }^{-}$). Good agreement was found between the isotherm values obtained by batch and column breakthrough studies for Solutions A and B. The Tc intra-particle diffusivity on ABEC resin was estimated by using VERSE simulations, and good agreement was found among a series of column-breakthrough experiments at varying flow velocities, column sizes, and Tc concentrations. However, testing of $10 \mathrm{cc}$ cartridges provided by NorthStar with Solutions A and B did not give satisfactory results as significant Tc breakthrough was observed, and ABEC cartridge performance varied widely among experiments. The inconsistent experimental results of Tc-99 uptake on the $10 \mathrm{cc}$ ABEC cartridges with Solutions A and B are believed to be due to inconsistent preparation of the $\mathrm{ABEC}$ resin prior to packing and/or inconsistent packing.

Based on discussions with NorthStar in November 2015, we determined that the ABEC polishing step should be removed from their front-end processing of the MURR Mo product. The ABEC polishing step was in place to remove Tc that had been produced from Mo-99 decay or been directly produced during irradiation from the Mo product. US Pharmacopeia studies on the Mo product both with and without the ABEC polishing step indicated very little change in purity. The ABEC column was eliminated from the process because the Mo product passed Pharmacopeia testing, and the experimental results on the ABEC column performance were inconsistent. 


\section{REFERENCES}

1. Rogers, R. D., Bond, A. H., Griffin, S. T. and Horwitz, E. P. New Technologies for Metal Ion Separations: Aqueous Biphasic Extraction Chromatography (ABEC). Part I Uptake of Pertechnetate. Solvent Extr. Ion Exch. 1996, 14, 919-946.

2. Rogers, R. D., Bond, A. H., Zhang, J. and Horwitz, E. P. New Technetium-99M Generator Technologies Utilizing Polyethylene Glycol-Based Aqueous Biphasic Systems. Sep. Sci. Technol. 1997, 32, 867-882.

3. Rogers, R. D., Griffin, S. T., Horwitz, E. P. and Diamond, H. Aqueous Biphasic Extraction Chromatography (ABEC $\left.{ }^{\mathrm{TM}}\right)$ : Uptake of Pertechnetate from Simulated Hanford Tank Wastes. Solvent Extr. Ion Exch. 1997, 15, 547-562.

4. Bond, A. H., Chang, F. W. K., Thakkar, A. H., Williamson, J. M., Gula, M. J., Harvey, J. T., Griffin, S. T., Rogers, R. D. and Horwitz, E. P. Ind. Eng. Chem. Res. 1999, 38, 1676-1682.

5. Berninger, J.A.; Whitley, R.D.; Zhang, X.; Wang N.-H.L. A Versatile Model for Simulation of Reaction and Nonequilibrium Dynamics in Multicomponent Fixed-Bed Adsorption Processes. Comput. Chem. Eng. 1991, 15, 749.

6. Whitley, R.D.; Van Cott, K. E.; Wang N.-H. L. Analysis of Nonequilibrium Adsorption Desorption Kinetics and Implications for Analytical and Preparative Chromatography. I\&EC Research 1993, 32, 149.

7. Van Cott, K.E.; Whitley, R. D.; Wang N.-H. L. Effects of Temperature and Flow Rate on Frontal and Elution Chromatography of Aggregating Systems. Sep. Technol. 1991, 1, 142.

8. Whitley, R.; Zhang, X.; Wang, N.-H. L. Protein Denaturation in Nonlinear Isocratic and Gradient Elution Chromatography. AIChE J. 1994, 40, 1067.

9. Yu, C.-M.; Mun, S.; Wang, N.-H. L. Theoretical Analysis of the Effects of Reversible Dimerization in Size Exclusion Chromatography. J. Chromatogr. A 2006, 1132, 99.

10. Tsui, H.-W.; Hwang, M. Y.; Ling , L.; Franses, E. I.; Wang N.-H. L. Retention Models and Interaction Mechanisms of Acetone and Other Carbonyl-containing Molecules with Amylose tris[(S)- $\alpha$-methylbenzylcarbamate] Sorbent. J. Chromatogr. A 2012, 1279, 36.

11. Ma, Z.; Whitley, R. D.; Wang, N.-H. L. Pore and Surface Diffusion in Multicomponent Adsorption and Liquid Chromatography Systems. AIChE J. 1996, 42, 1244.

12. Chung, P.-L.; Bugayong, J. G.; Chin, C. Y.; Wang, N.-H. L. A Parallel Pore and Surface Diffusion Model for Predicting the Adsorption and Elution Profiles of Lispro Insulin and Two Impurities in Gradient-Elution Reversed Phase Chromatography. J. Chromatogr. A 2010, 1217, 7100 . 
13. Sato, H., Yui, M., Yoshikawa, H. Ionic Diffusion Coefficients of $\mathrm{Cs}^{+}, \mathrm{Pb}^{2+}, \mathrm{Sm}^{3+}, \mathrm{Ni}^{2+}$, $\mathrm{SeO}_{4}{ }^{2-}$ and $\mathrm{TcO}_{4}{ }^{2-}$ in Free Water Determined from Conductivity Measurements. J. Nucl. Sci. Technol. 1996, 33, 950-955.

14. Cussler, E. L., Breuer, M. M. Accelerating Diffusion in Mixed Solvents. AIChE J. 1972, 18, 812-816.

15. Havenga, E., Leaist, D. G. Salting out and Coupled Diffusion in Aqueous Dioxane and Aqueous Propan-2-ol Mixed Solvents. J. Chem. Soc., Faraday Trans. 1998, 94, 3353-3358.

16. Hand, D., Crittenden, J., and Thacker, W. Simplified Models for Design of Fixed-Bed Adsorption Systems. J. Environ. Eng., 1984, 10, 440-456.

17. Reed, B., E., Jamil, M., Thomas, B. Effect of pH, Empty Bed Contact Time and Hydraulic Loading Rate on Lead Removal by Granular Activated Carbon Columns. Water Environ. Res. 1996, 68, 877-882.

18. Wilson, E. J.; Geankoplis, C. J. Liquid Mass Transfer at Very Low Reynolds Numbers in Packed Beds. Ind. Eng. Chem. Fundam. 1966, 5, 9-14.

19. Chung, S. F.; Wen, C. Y. Longitudinal Dispersion of Liquid Flowing Through Fixed and Fluidized Beds. AIChE J. 1968, 14, 857-866. 
This page intentionally left blank 



\section{Argonne}

\section{Nuclear Engineering Division}

Argonne National Laboratory

9700 South Cass Avenue, Bldg. 208

Argonne, IL 60439-4854

www.anl.gov

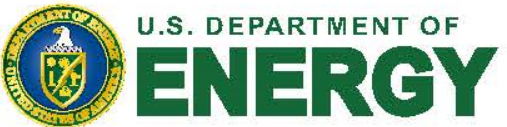

Argonne National Laboratory is a U.S. Department of Energy

laboratory managed by UChicago Argonne, LLC 